\title{
Heat Exchangers for Heavy Vehicles Utilizing High Thermal Conductivity Graphite Foams
}

James Klett, Ron Ott and April McMillan

Oak Ridge National Lab. 
SAE routinely stocks printed papers for a period of three years following date of publication. Direct your orders to SAE Customer Sales and Satisfaction Department.

Quantity reprint rates can be obtained from the Customer Sales and Satisfaction Department.

To request permission to reprint a technical paper or permission to use copyrighted SAE publications in other works, contact the SAE Publications Group.

This article was prepared as an account of work sponsored by an agency of the United States

Government. Neither the United States Government nor any agency thereof, nor any of their employees, makes any warranty, express or implied, or assumes any legal liability or responsibility for the accuracy, completeness, or usefulness of any information, apparatus, product, or process disclosed, or represents that its use would not infringe privately owned rights. Reference herein to any specific commercial product, process, or service by trade name, trademark, manufacturer, or otherwise does not necessarily constitute or imply its endorsement, recommendation, or favoring by the United States Government or any agency thereof. The views and opinions of authors expressed herein do not necessarily state or reflect those of the United States Government or any agency thereof.

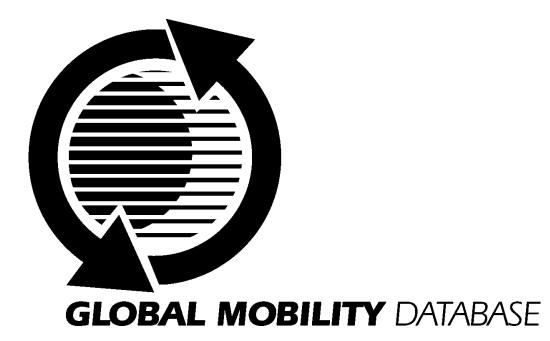

All SAE papers, standards, and selected books are abstracted and indexed in the Global Mobility Database

ISSN 0148-7191

No copyright is asserted in the works of U.S. Government employees.

Positions and opinions advanced in this paper are those of the author(s) and not necessarily those of SAE. The author is solely responsible for the content of the paper. A process is available by which discussions will be printed with the paper if it is published in SAE Transactions. For permission to publish this paper in full or in part, contact the SAE Publications Group.

Persons wishing to submit papers to be considered for presentation or publication through SAE should send the manuscript or a 300 word abstract of a proposed manuscript to: Secretary, Engineering Meetings Board, SAE.

\section{Printed in USA}




\title{
Heat Exchangers for Heavy Vehicles Utilizing High Thermal Conductivity Graphite Foams
}

\author{
James Klett, Ron Ott and April McMillan \\ Oak Ridge National Lab.
}

No copyright is asserted in the works of U.S. Government employees

\begin{abstract}
Approximately two thirds of the world's energy consumption is wasted as heat. In an attempt to reduce heat losses, heat exchangers are utilized to recover some of the energy. A unique graphite foam developed at the Oak Ridge National Laboratory (ORNL) and licensed to Poco Graphite, Inc., promises to allow for novel, more efficient heat exchanger designs. This graphite foam, Figure 1, has a density between 0.2 and $0.6 \mathrm{~g} / \mathrm{cm}^{3}$ and a bulk thermal conductivity between 40 and $187 \mathrm{~W} / \mathrm{m} \cdot \mathrm{K}$. Because the foam has a very accessible surface area $\left(>4 \mathrm{~m}^{2} / \mathrm{g}\right)$ and is open celled, the overall heat transfer coefficients of foam-based heat exchangers can be up to two orders of magnitude greater than conventional heat exchangers. As a result, foam-based heat exchangers could be dramatically smaller and lighter.
\end{abstract}

\section{INTRODUCTION}

Contemporary thermal management has centered around aluminum and copper heat sinks and substrates. This is due to the very high thermal conductivity $(180 \mathrm{~W} /$ $\mathrm{m} \cdot \mathrm{K}$ for aluminum 6061 and $400 \mathrm{~W} / \mathrm{m} \cdot \mathrm{K}$ for copper). However, when weight is taken into account, the specific thermal conductivity (thermal conductivity divided by specific gravity) is only $\sim 54$ and $45 \mathrm{~W} / \mathrm{m} \cdot \mathrm{K}$ respectively. Therefore, in automotive applications, where weight is a significant concern, it is imperative that a lighter weight thermal management material be found.

Mesophase pitch-derived graphitic foam, on the other hand, can be considered as an interconnected network of graphitic ligaments and, thus, should exhibit isotropic material properties. More importantly, such a foam will exhibit extremely high thermal conductivities along the ligaments of the foam (up to 5 times better than copper) and, therefore, will exhibit high bulk thermal conductivities. Metallic foams, on the other hand, are also being explored as a potential thermal management material. However, the thermal conductivities are still low, $5-50 \mathrm{~W} / \mathrm{m} \cdot \mathrm{K}(1)$. Existing carbon foams are typically reticulated glassy carbon foams with a pentagonal dodecahedron structure (2, 3,4 ) and exhibit thermal conductivities less than $1 \mathrm{~W} / \mathrm{m} \cdot \mathrm{K}$
$(1,5,6,7)$. The pitch-derived graphitic foams reported here, Figure 1, exhibit a spherical morphology, and present a unique solution to this problem by offering high thermal conductivity with a low weight.

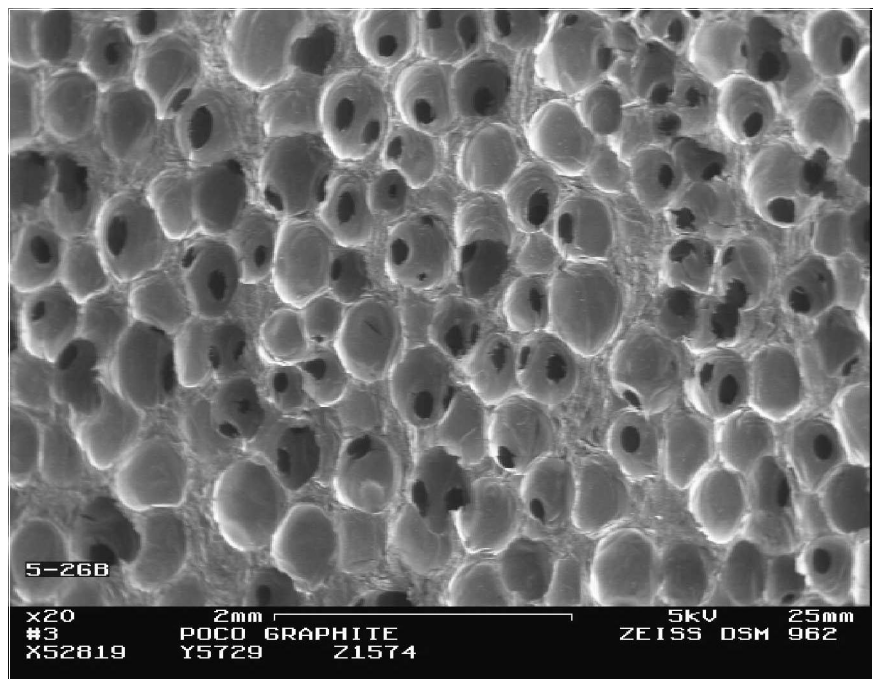

Figure 1. High Thermal Conductivity Graphite Foam.

Two devices are currently used for thermal management: heat exchangers, which transfer heat energy from one area of a device to another, and heat sinks, which absorb heat. Currently, most cooling heat exchangers for highpower electronics use layers of water-cooled aluminum or copper plate mounted below the electrical circuitry to transfer heat from hotter areas to cooler areas. This presents a unique problem in that if a crack or leak forms, then the water would short the circuitry and destroy the units. By using high thermal conductivity graphitic foam as the core material for these heat exchangers, the effective transfer of heat can be significantly increased while reducing the size and weight of the heat exchanger. But more importantly, it is potentially possible to utilize air to cool the device, thereby removing the water from the system.

A new, less time consuming process for fabricating mesophase pitch-based graphitic foams without the traditional blowing and stabilization steps has been developed at Oak Ridge National Laboratory (ORNL) and is the 
focus of this research. Initially these foams possess a thermal conductivity of $106 \mathrm{~W} / \mathrm{m} \cdot \mathrm{K}$ at a relatively low density of $0.54 \mathrm{~g} / \mathrm{cm}^{3}$. Potentially, the process will lead to a significant reduction in the cost of graphitic-based thermal management materials (i.e. foam-reinforced composites and foam core sandwich structures).

HEAT EXCHANGER APPLICATIONS - In a test to demonstrate the ability of the foam to transfer heat in a heat exchanger application, a block of foam 10.1 centimeter (cm) square by $2.54 \mathrm{~cm}$ thick was fitted with three aluminum tubes $(0.635 \mathrm{~cm}$ diameter) as shown in Figure 2 . The foam exhibited a density of approximately $0.5 \mathrm{~g} / \mathrm{cm}^{3}$ and a thermal conductivity of approximately $150 \mathrm{~W} / \mathrm{m} \cdot \mathrm{K}$. Water flowing at 11.34 liters per minute and $80^{\circ} \mathrm{C}$ was pumped through the tubes and ambient air at 560 liters per minute at 25 degrees Celsius was forced through the foam (in a duct type arrangement). The temperature drop of the water was measured to be approximately $3^{\circ} \mathrm{C}$ and the temperature change of the air was recorded. Strikingly, the temperature of the ambient air passing through the foam increased by up to $30^{\circ} \mathrm{C}$ (unlike most heat exchangers of this size).

The overall heat transfer coefficient was calculated to be between 6,000 and $11,000 \mathrm{~W} / \mathrm{m}^{2} \cdot \mathrm{K}$ and was dependent upon humidity. This is different from most air/water heat exchangers where humidity does not affect heat transfer coefficient significantly. Most air/water heat exchangers, like a radiator on a car, exhibit a overall heat transfer coefficient of about $30-45 \mathrm{~W} / \mathrm{m}^{2} \cdot \mathrm{K}$. While this test demonstrates a remarkable increase in heat transfer coefficient and provides the tool to reduce the size of heat exchangers dramatically, the pressure drop through the foam was approximately $5.4 \mathrm{kPa} / \mathrm{cm}$. This is not unreasonable for land-based systems where developing a pressure head is feasible. However, in an automobile or airplane where weight and power is a significant concern, this large pressure drop presents a potential problem for an efficient design.

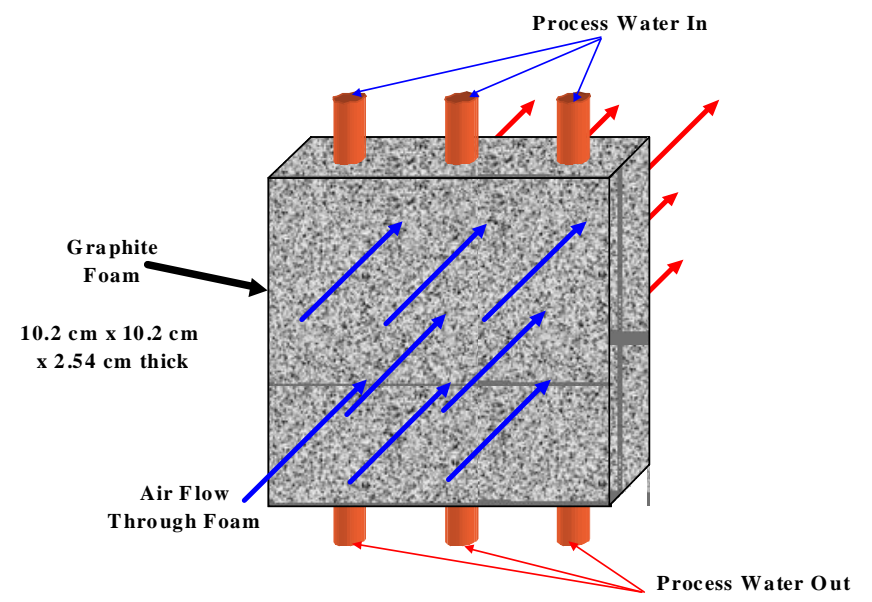

Figure 2. Schematic representation of heat exchanger with cooling air forced through pores of foam. Overall heat transfer coefficient measured at $11,000 \mathrm{~W} / \mathrm{m}^{2} \cdot \mathrm{K}$.
Because the pressure drop was significant a design similar to a current radiator was constructed as shown schematically in Figure 3 to reduce pressure drop. This new design, targeted for an $800 \mathrm{hp}$ racing engine, accounted for the need for very high surface area of the external fins of foam. The specific design cannot be shown due to its proprietary nature; however, the total external fin surface area was $7561 \mathrm{~cm}^{2}$. Aluminum 6061 tubes with an internal dimension of $0.782 \mathrm{~cm}$ were press-fit through the foam and then the fins and through holes were machined out of the foam. The through holes in this system yielded a very small resistance to air flow and, remarkably, a 0.03 $\mathrm{kPa} / \mathrm{cm}$ pressure drop through the system was achieved. There were several rows of finned tubes (not shown in Figure 10) ducted to a fan providing 39,300 liters per minute of ambient air (dramatically smaller than the approximately 1.7 million liters per minute of air at 180 $\mathrm{mph}$ that the cars currently operate). The overall dimensions of the radiator was $22.9 \mathrm{~cm} \times 17.78 \mathrm{~cm} \times 15.27 \mathrm{~cm}$ deep, and significantly smaller than the current radiators. The hot engine coolant (pure water) was maintained at 57.5 liters per minute at $99.4^{\circ} \mathrm{C}$ in a steady state test. At steady state, the water coolant temperature dropped from $99.4^{\circ} \mathrm{C}$ to $91^{\circ} \mathrm{C}$, which is the desired engine inlet coolant temperature (inlet temperatures below this will reduce efficiencies of the engine). At the given coolant flow rate, this is equivalent to $33.5 \mathrm{~kW}$ of heat rejected to the air and an increase from ambient of approximately $43^{\circ} \mathrm{C}$ for dry air. The overall heat transfer coefficient was calculated to be $977 \mathrm{~W} / \mathrm{m}^{2} \cdot \mathrm{K}$ and since the desired inlet coolant temperature was achieved, this was deemed a successful test.

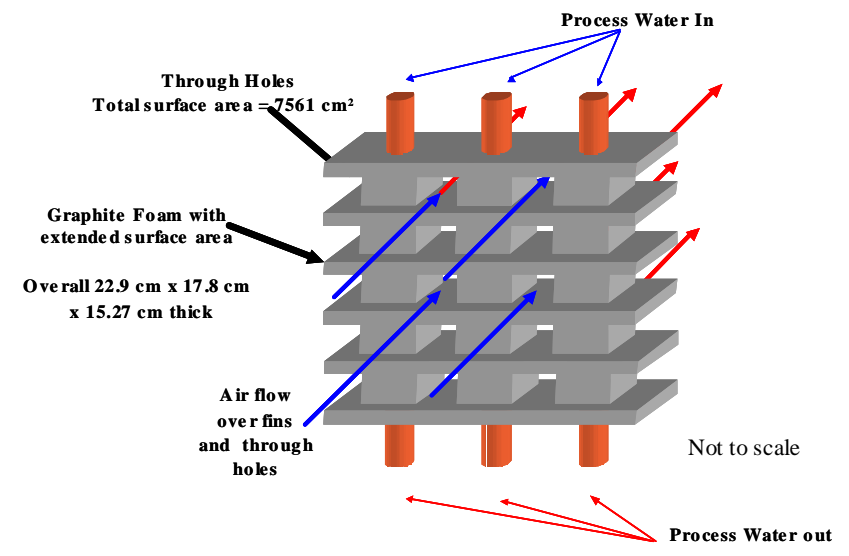

Figure 3. Schematic representation of heat exchanger with enhanced surface area machined into foam for enhanced heat transfer and reduced pressure drop. Note that several rows of this design were employed in the final version.

\section{HEAT SINKS}

In order to characterize the behavior of the foam as a sink material for power electronics, a test chamber (Figure 4) was built to quantify its power dissipation capacity. As shown in Figure 2, the foam is mounted to an aluminum plate (usually by brazing) and placed in a cavity where 
the cooling fluid flows. The system is designed with no gap around the foam, thereby forcing the fluid to pass through the pores of the foam. The system is sealed with o-rings, and pressure taps are inserted into the chamber to measure the pressure drop of the system. A simulated power inverter (cartridge heaters in a $5 \mathrm{~cm} \times 5 \mathrm{~cm} \times 2 \mathrm{~cm}$ aluminum block) is mounted to the aluminum plate and is capable of generating up to 800 Watts $\left(32 \mathrm{~W} / \mathrm{cm}^{2}\right)$. As the cooling fluid passes through the system, the temperatures of the heater and inlet and outlet fluid are measured. The overall heat transfer coefficient $\left(U_{0}\right)$ is calculated from Equation (1) where $\Delta T_{L M}$ is the log mean temperature difference, $A$ is the area of foam attached to the aluminum plate, and $q$ is the heat dissipated to the cooling fluid.

$$
\mathrm{U}_{\mathrm{o}}=\mathrm{q} /\left(\mathrm{A} \cdot \Delta \mathrm{T}_{\mathrm{LM}}\right)
$$

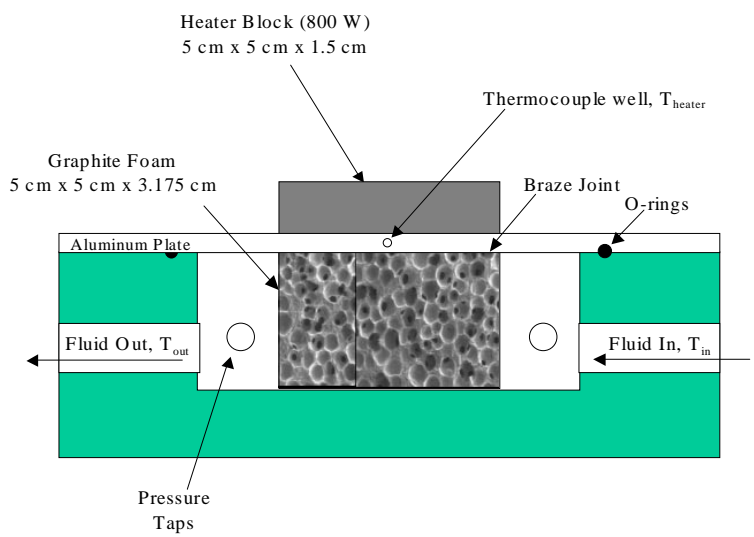

Figure 4. Schematic of test rig.

\section{RESULTS}

In the first experiment a solid block of foam $(5 \mathrm{~cm} \times 5 \mathrm{~cm}$ $x 3.175 \mathrm{~cm}$ ) at a density of $0.47 \mathrm{~g} / \mathrm{cm}^{3}$ was brazed to the aluminum using SuperBraze ${ }^{\circledR}$ low temperature braze. Ambient air was passed through the foam at 140, 280, and 420 liters per minute. The temperature of the heater versus heater power density at various flow rates is plotted in Figure 5. The overall heat transfer coefficient versus airflow is plotted in Figure 6 and the pressure drop is plotted in Figure 7. The overall heat transfer coefficient is very high compared to that of a standard automobile radiator $\left(2500 \mathrm{vs} .30 \mathrm{~W} / \mathrm{m}^{2} \cdot \mathrm{K}\right)$.

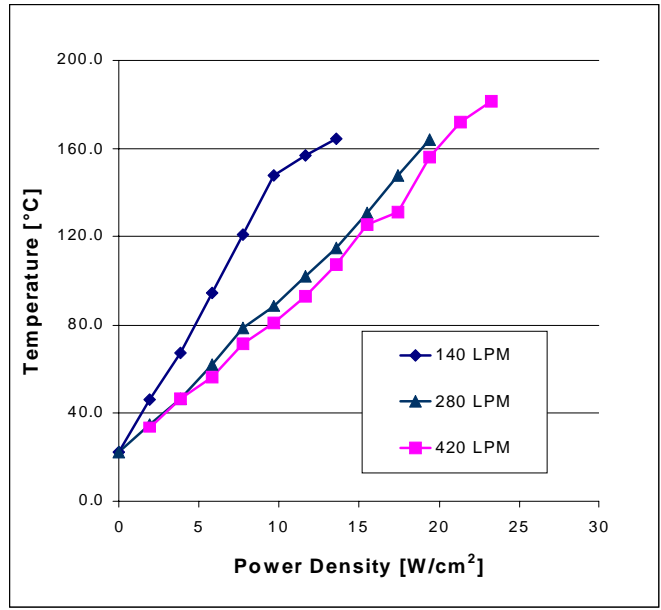

Figure 5. Temperature vs. Power.

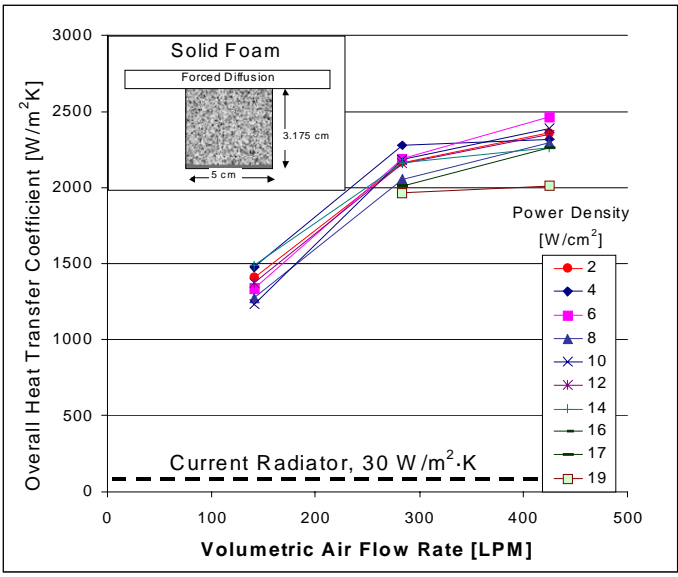

Figure 6. Overall heat transfer coefficients.

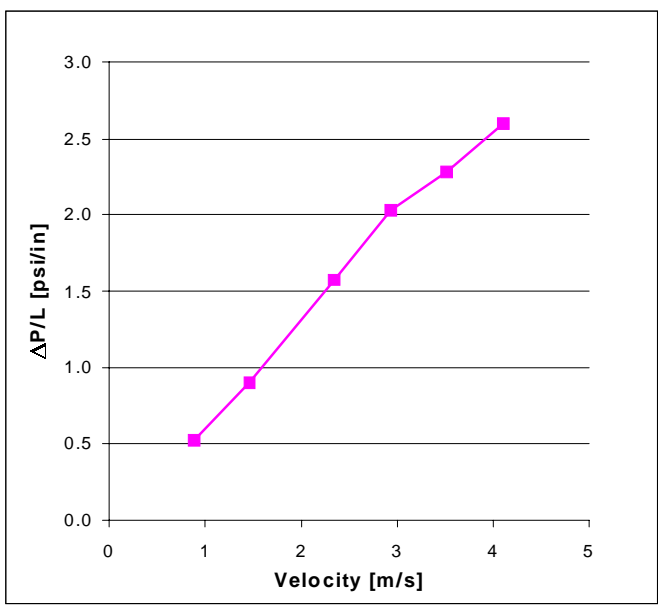

Figure 7. Pressure drop through the foam. 


\section{CONCLUSIONS}

The high conductivity graphite foam presents a unique solution to the increasing cooling demands of power electronics and other automotive components. With novel designs, it is possible to eliminate cooling water and utilize air as the primary cooling fluid. This is a logical step since the heat is rejected to air eventually. In a parallel effort, radiators designed with the carbon foam exhibit a 10 -fold increase in heat transfer coefficients. Higher heat-transfer coefficients should lead to significant reductions in the number of tubes (i.e. reduction in surface area) needed for similar heat transfer. Therefore, a typical automotive radiator that is $48 \mathrm{~cm} \times 69 \mathrm{~cm}$ might be reduced to $20 \mathrm{~cm} \times 20 \mathrm{~cm}$ in cross section with the same heat removal rate. Such a reduced size will reduce overall weight, cost, and volume of the system, thereby improving fuel efficiency.

\section{ACKNOWLEDGMENTS}

Research sponsored by the U.S. Department of Energy, Assistant Secretary for Energy Efficiency and Renewable Energy, Office of Transportation Technologies, as part of the Advanced Automotive Materials Program, under Contract No. DE-AC05-96OR22464 with Lockheed Martin Energy Research Corporation

\section{REFERENCES}

1. Gibson LJ, Ashby, MF. Cellular Solids: Structures \& Properties, Pergamon Press, New York, 1988.

2. Glicksman LR, Torpey M. Proceedings of the Polyurethane World Congress, Aachen, Germany, 1987.

3. Glicksman LR, Marge AL, Moreno JD. Developments in Radiative Heat Transfer, ASME HTD 1992;203.

4. Kuhn J, Int. J. Heat Mass Transfer 1992;35(7):17951801.

5. Glicksman, LR, Schuetz M, Sinofsky M. A Study of Radiative Foam Heat Transfer through Foam Insulation. Report prepared by Massachusetts Institute of Technology under subcontract No. 19X-09099C, 1988.

6. Ultramet Product Literature, 1998.

7. Doermann D, Sacadura JF. J. of Heat Transfer 1996;118:88-93. 